\title{
Design and Application of Mobile Testing Laboratory for Current Transformer
}

\author{
SHI Qiang ${ }^{1, a}$, LI Weiwei ${ }^{2, b}$, HUANG Jiapeng ${ }^{1}$ \\ ${ }^{1}$ Sichuan Electric Power Corporation Metering Center, Chengdu 610072, China \\ ${ }^{2}$ State Grid Sichuan Electric Power Research Institute, Chengdu, 610000, China \\ aemail:awaityou1986@gmail.com, bemail: liweiwei0830@163.com
}

Keywords: Current transformer; Calibration test; Mobile Laboratory

\begin{abstract}
In response to the growing requirements of on-site calibration test of transformers in power system, a mobile testing laboratory for current transformer was designed, based on the comparative measurement stipulated by the national verification procedures. Mounted in the industrial container, the mobile laboratory includes various instruments and equipments used in the test. Compared with traditional methods, the laboratory overcomes lots of shortcomings, such as carrying equipments hard, wiring complexity and so on. It is easy to carry out experiments just by providing power supply, primary side and secondary side wiring. The application results showed that the mobile laboratory was simple, convenient, stable and reliable, significantly reducing the labor intensity of workers and improving work efficiency. Introduction

With the rapid development of the power system, the number of metering transforms used in the power grid increased. The measurement error of transformers, which relates to energy metering and trade settlement, belongs to the state compulsory verification project. Therefore, the efficiency of verification measurement for transformers attracts more and more attention. In accordance with the regulation [1], a large amount of testing equipment is needed in the on-site testing of current transformers, such as standard current transformers, voltage regulators and so on. When the current is greater than 2000A, the power capacity doubled. In that case, the equipment is too heavy to move, and the connection is difficult, leading to great inconvenience during on-site testing.

Nowadays, the measuring cars and mobile testing devices for transformers have been a hot topic, because of multi-functions and convenient application [2-5]. According to the actual work needs, this work designed a mobile testing laboratory for on-site verification of current transformer, based on the principle of comparative method. All testing equipments were installed in a container, what is convenient to connect. The system is capable of measuring errors of current transformers, whose greatest rated current is $5000 \mathrm{~A}$, and highest degree of accuracy is 0.1 . It overcomes many disadvantages of the traditional testing method, for example, moving devices hard, wiring in disorder et al. The laboratory is simple to operate and transport, which not only improve the work efficiency significantly, but also ensure safety of stuffs and equipments, and reduce outage time for maintenance.
\end{abstract}

\section{Working Principle of Mobile Laboratory}

Comparative method was used in this mobile laboratory to test the measurement error, that is, current difference between the secondary side of the test transformer and that of standard transformer. The ratio difference $f_{\mathrm{x}}(\%)$ and phase difference $\delta_{\mathrm{x}}\left({ }^{\prime}\right)$ can be got directly from the transformer calibrator, when the test CT connect with standard CT at primary side and the current difference at the secondary side between them being input to calibrator. Rated transformation ratio of standard transformer should be the same with that of test's, while the accuracy of standard transformer should be at least two grades higher than that of test transformer and the actual error should be less than one fifth of the basic error limits of test transformer. Figure 1 gives schematic for the error measuring wiring of current transformer. 


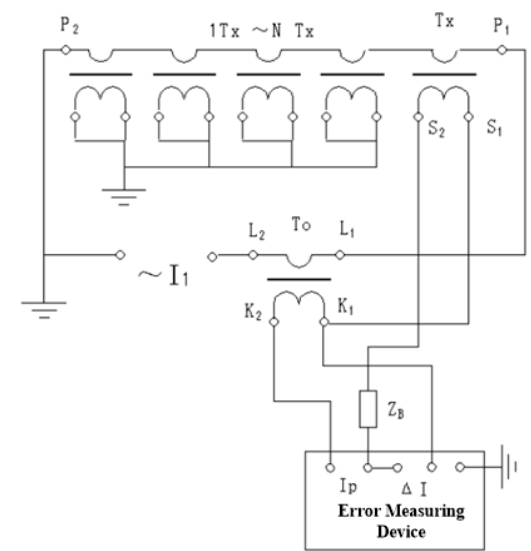

Fig.1. Schematic for error measuring wiring of current transformer

To refers to the standard current transformer, Tx refers to the test current transformer, $Z_{B}$ is current load box, and $1 \mathrm{Tx} \sim \mathrm{NTx}$ are transformers which share the same primary winding with the tested current transformer . The terminal $\mathrm{P}_{1}$ at the primary winding of test transformer is connected with terminal $\mathrm{L}_{1}$ at the primary winding of standard transformer, and the terminal $\mathrm{S}_{1}$ at the secondary winding of test transformer is connected with terminal $\mathrm{K}_{1}$ at the secondary winding of standard transformer.

\section{Technical Solutions and Features}

The mobile laboratory, which can provide large current booster and verification device, includes standard current transformer, power source, voltage regulator, current booster unit, current load box, reactive power compensation device, transformer calibrator etc. Each part not only can be used alone, but also can match with each other to adjust the actual conditions. All these parts mentioned above are mounted in a commercial container whose size is $5.69 \mathrm{~m} \times 2.13 \mathrm{~m} \times 2.18 \mathrm{~m}$, as shown in Fig.2.

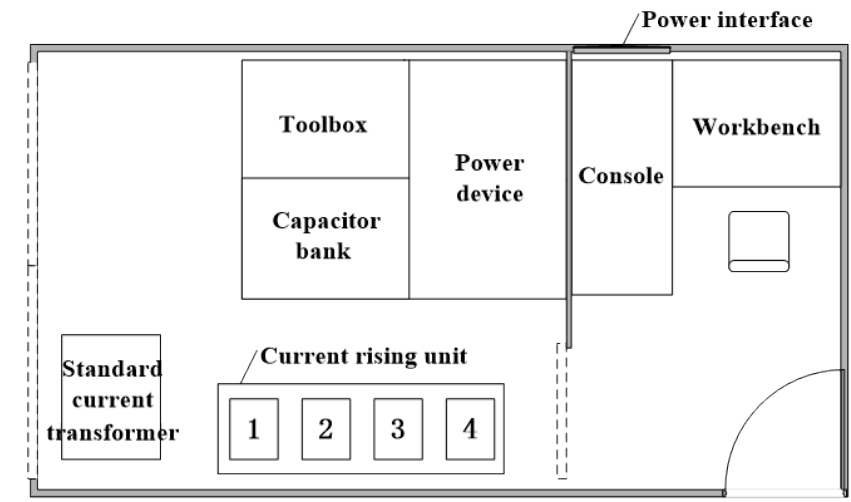

Fig.2. Schematic diagram of the internal structure in mobile laboratory

As shown in Fig.2, the structure design of mobile laboratory mainly has the following features: (1)The laboratory consists of test region on the left and control region on the right (the console, which is provided with a power switch, pressure regulator, calibrator, and load box, is easy to control). (2)The double doors at the end of the laboratory can be opened to benefit the wiring of current wires. (3)The on-site test can be carried out quickly just by supplying source and completing primary and secondary current line connection. The technical indexes and characteristics of main equipment are shown as follows:

(1) Design of power source. Heavy current boosters during on-site testing of current transformer need large capacity power source, for the inductive impedance of current transformer circuit accounted for $70 \%-90 \%$. In order to reduce the requirements of on-site test power and improve the power efficiency, power electronic devices were selected as the power to access device in the mobile laboratory. The three-phase $220 \mathrm{~V}$ power source was transformed to single-phase power 
source for the devices through the rectifying and inverting. The $50 \mathrm{~Hz}$ test power source, whose capacity of power source is not less than 150kVA, is three-phase four wire system. The output voltage after conversion of power supply unit is $220 \mathrm{~V}$, the frequency is $50 \mathrm{~Hz} \pm 0.5 \mathrm{~Hz}$, and distortion factor of frequency waveform is less than $5 \%$.

(2) Standard current transformer. In order to meet the calibration requirement for various ratios of current transformer, the parameters of standard current transformer are shown as follows: (1)rated primary current: 5 5000A; (2)rated secondary current: 5A, 1A; (3)accuracy: $0.02 \mathrm{~S}$. This standard with good linearity and overload capacity can carry out error comparison for current transformer with rated primary current no more than 5000A, within the $120 \%$ range.

(3) Current booster unit. Four current boosters are mounted in the laboratory, and theirs parameters are shown as follows: (1)the capacity of current booster: 40kVA; (2)the input voltage of current booster: 0 400V; (3each turn voltage: 7V, (4the output current: 0 6000A.

The unit is composed of current boosters mentioned above, and its circuit structure is shown in Fig.2. The output of each current booster wound 2 turns is about $2.85 \mathrm{kA}$ and $14 \mathrm{~V}$, so the unit's is $5.7 \mathrm{kA}$ and $28 \mathrm{~V}$. According to the impedance of actual circuit, there are different combinations of 4 current boosters by controlling their switch.

(4) Reactive power compensation devices. The capacitors in series or parallel are used as reactive power compensation device, for the circuit inductance of current transformer is greater than the resistance. Adjust the capacitance until the capacitive reactive power is equal to inductive reactive power, to significantly reduce the capacity requirements of power source, voltage regulator and current booster. In this work, the capacitors is in parallel with current booster, as shown in Fig.4, where YT refers to voltage regulator, ST refers to current booster, $\mathrm{R}$ is the equivalent resistance of circuit, $\mathrm{Z}_{\mathrm{L}}$ is the equivalent inductance, and $\mathrm{C}$ is the compensation capacitor.

The advantage of this system is that, the primary side is electrical isolated from the second side by the current booster. The compensation capacitor at the primary side can work normally even when the potential of test circuit is high [6]. Under the condition of complete compensation, the power source and voltage regulator only supply the active power, while the current booster would provide all the active and reactive power capacity. There are 4 compensation capacitor groups which correspond to the 4 current boosters. Each capacitor group consists of 38 small capacitor units which can be switched and broken by the switch. Electron source can measure and show real-time power factor, the appropriate number of compensation capacitor can be chosen to improve the power factor according to the real circuit.

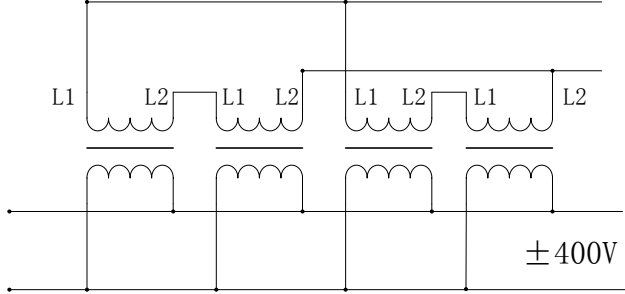

Fig.3. Series and parallel circuit of current boosters

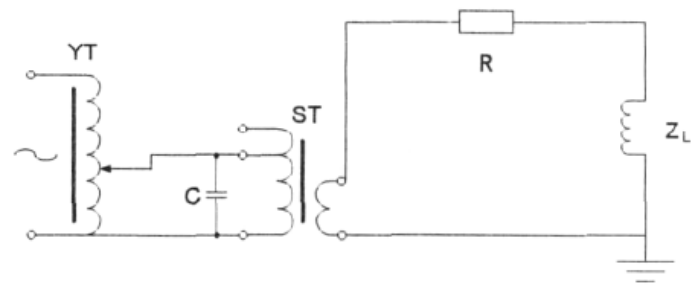

Fig.4. Test schematic diagram of shunt capacitors at current booster's primary side

\section{Application Effect}

The laboratory had played important roles at the on-site test of current transformer in large-scale projects, such as 500kV Honggou transformer substation, Xiluodu hydropower station, and Jinping hydropower station. As shown in the practical application, the test process and mode of the mobile laboratory are clear and flexible, the test results are stable and reliable, leading to high work efficiency. Fig.5 gives the on-site tests of this laboratory in $500 \mathrm{kV}$ Honggou transformer substation and Xiluodu hydropower station. 

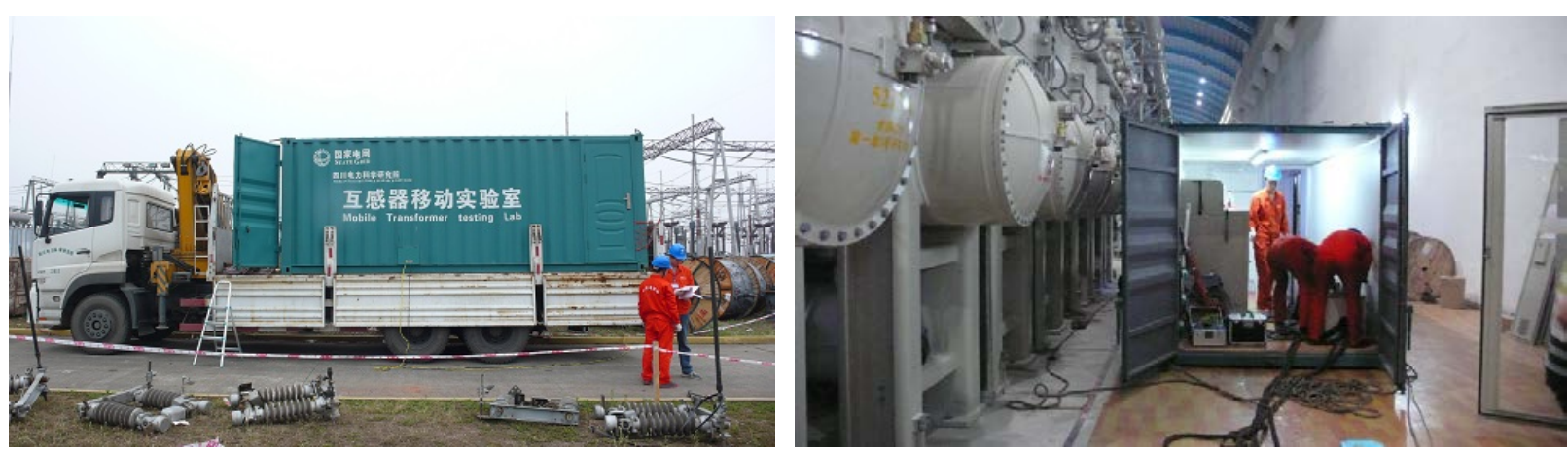

Fig.5. Mobile testing laboratory for current transformer applied at 500kV Honggou Transformer Substation and Xiluodu Hydropower Station

The test objects in Xiluodu Hydropower are $21550 \mathrm{kV}$ current transformers (in GIS) made in Xian XD High Voltage Apparatue Co. LTD, whose rated transformation ratio is 4000/1A, accuracy class is $0.1 \mathrm{~S}$. Conducting wire is used to connect grounding switch on both sides of the transformer in GIS to form a closed circuit. The length of this circuit is no more than $40 \mathrm{~m}$. The test parameter is shown in Table 1.

Table 1. Parameter measurement results of 550kV CT tests

\begin{tabular}{lccccccc}
\hline specimen & $\begin{array}{c}\text { Test } \\
\text { current /A }\end{array}$ & $\begin{array}{c}\text { Output } \\
\text { voltage of } \\
\text { regulator } \\
\text { /V }\end{array}$ & $\begin{array}{c}\text { Output } \\
\text { current of } \\
\text { regulator } \\
\text { /A }\end{array}$ & $\begin{array}{c}\text { Power factor of } \\
\text { regulator cos } \Phi\end{array}$ & $\begin{array}{c}\text { Output } \\
\text { capacity of } \\
\text { regulator /kVA }\end{array}$ & $\begin{array}{c}\text { Output } \\
\text { capacity of } \\
\text { current } \\
\text { booster /kVA }\end{array}$ & $\begin{array}{c}\text { Number of } \\
\text { compensation } \\
\text { capacitor }\end{array}$ \\
\hline A phase of XX line & 800 & 60.3 & 19.5 & 0.907 & 1.18 & 22.1 & 72 \\
A phase of XX line & 4000 & 317 & 98 & 0.908 & 31.1 & 110 & 72 \\
B phase of XX line & 800 & 65.3 & 19.2 & 0.904 & 1.25 & 22.3 & 52 \\
B phase of XX line & 4000 & 338 & 94 & 0.910 & 31.7 & 108 & 52 \\
\hline
\end{tabular}

The compensation capacitor of A phase differs from that of B phase, for the lengths of two test circuits are different. As shown in Table 1, the capacitive reactive of parallel capacity compensates most of inductive reactive, therefore the power source and the regulator just provide the active power and a small part of the reactive power. Take A phase whose current is 4000A as an example, $\mathrm{P}=\mathrm{UI}=31.1 \mathrm{kVA}$. While for the current booster, the inductive reactive at secondary side of current booster can't be compensated, because the parallel compensation capacitor is set at the primary side. Therefore the output capacity of current booster is all complex power. In this work, the measured output capacity of current booster is about $110 \mathrm{kVA}$, which is 3 times of output power of regulator. On the technical view, the mobile laboratory is capable of meeting most of on-site test requirements for current transformers

\section{Conclusion}

Based on the requirement of on-site test of current transformer, the mobile testing laboratory for current transformer is developed according to the standard methods, what overcomes the problems of traditional on-site measurement and verification work for current transformer. The results showed that, the mobile laboratory is convenient to transport and its measurement results is reliable. This laboratory greatly reduces the labor intensity of workers, improves the work efficiency, and is benefit for the growing demand of on-site test of current transformer.

\section{References}

[1] The state bureau of quality and technical supervision. JJG 1021-2007 Verification Regulation of Instrument Transformers in Power System [S]. Beijing: China metrology press, 2007. (in Chinese)

[2] Zhao Yitao, Zhang Baoguo. HLE1 Current Transformer Locale Calibration Device [J]. Electrical Measurement \& Instrumentation, 2004, 41(460): 48-51. (in Chinese)

[3] Zhao Xiumin, Zhao Yitao. Error Test of Current Transformers with Low-voltage Deduced 
Method [J]. Electrical Measurement \& Instrumentation, 2004, 41(468): 28-30. (in Chinese)

[4] Wang Hongsheng, Fang Yazhong, Zhang Yuming. A Portable Field Checking Instrument of TA[J]. North China Electric Power, 2006, 11: 008. (in Chinese)

[5] Yang Xiaoxi, Song Xiaolin, Zhang Fei, et al. Development of high current up-flow device for 750kV current transformer [J]. Shaanxi Power, 2009, 36(9): 22-26. (in Chinese)

[6] Zhang Shuhan, Li Qian, Wu Liangke, et al. High-current Generating Methods for On-site Calibration Tests of GIS Current Transformers [J]. Electrical Measurement \& Instrumentation, 2009, 46(12): 6-8. (in Chinese) 